Kansas State University Libraries

New Prairie Press

\title{
LITTER MATE CORRELATIONS IN THE WEIGHT OF PIGS
}

Thomas Kirchoff

D. F. Cox

Follow this and additional works at: https://newprairiepress.org/agstatconference

Part of the Agriculture Commons, and the Applied Statistics Commons

\section{(c) $($ ) $\ominus$}

This work is licensed under a Creative Commons Attribution-Noncommercial-No Derivative Works 4.0 License.

\section{Recommended Citation}

Kirchoff, Thomas and Cox, D. F. (1993). "LITTER MATE CORRELATIONS IN THE WEIGHT OF PIGS,"

Conference on Applied Statistics in Agriculture. https://doi.org/10.4148/2475-7772.1385

This is brought to you for free and open access by the Conferences at New Prairie Press. It has been accepted for inclusion in Conference on Applied Statistics in Agriculture by an authorized administrator of New Prairie Press. For more information, please contact cads@k-state.edu. 


\title{
Litter Mate Correlations in the Weight of Pigs ${ }^{1}$
}

\author{
Thomas Kirchoff and D.F. Cox \\ Iowa State University \\ Ames, Iowa 50011
}

\begin{abstract}
Competition may influence the weights of animals confined to litters or pens, if conditions occur that limit the space and the feed provided, by inducing a negative correlation among the weights within the groups. An example of the phenomenon appeared in the birthweight of pigs where the intra-class correlation declined in a linear manner with increasing litter size. The data consisted of records on 33,165 pigs from 3282 litters raised on a single farm.
\end{abstract}

\section{Introduction}

A simple model for the weight of animals raised in groups uses the assumption of independent residuals with a common variance within groups. This implies a constant intra-class correlation over all group sizes. An investigation of the appropriateness of these assumptions utilized the records on pig weight gathered over 17 separate seasons, from two breeds, at an Iowa State University research farm.

\section{Background}

The weight, $w$, of an animal from a group or litter has two components, an effect common to the group, $g$, and an effect unique to the animal, e. A common model and the form of the associated analysis of variance for litters of size $n$ states:

$$
w=g+e
$$

where $g$ and $e$ are random with variances, $\sigma_{g}^{2}$ and $\sigma_{e}^{2}$.

\begin{tabular}{ll} 
Source & Expectations of Mean Squares \\
\hline Among Litters & $\sigma_{e}^{2}+n \sigma_{g}^{2}$ \\
Animals within Litters & $\sigma_{e}^{2}$ \\
\hline
\end{tabular}

An alternative form defines $\rho=\sigma_{g}^{2} /\left(\sigma_{g}^{2}+\sigma_{e}^{2}\right)$ and $\sigma_{w}^{2}=\sigma_{g}^{2}+\sigma_{e}^{2}$ so that the expected mean squares appear as:

\begin{tabular}{ll} 
Source & Expectations of Mean Squares \\
\hline Among Litters & $\sigma_{w}^{2}(1+(n-1) \rho)$ \\
Animals within Litters & $\sigma_{w}^{2}(1-\rho)$ \\
\hline
\end{tabular}

${ }^{1}$ Journal Paper No. J-15433 of the Iowa Agriculture and Home Economics Experiment Station, Ames, Iowa. Project No. 0101. 
All of the preceding assumes that $\rho$, the intra-class correlation, does not depend on $n$, the group or litter size. The latter form of the expectations actually predates the analysis of variance $[1]$.

In a situation of limited resources and space it seems reasonable that a negative correlation could arise among the animals in a group; one animal gets larger at the expense of another unable to compete as well. Such a tendency would increase the variance within groups and reduce the estimate of intra-class correlation. Further, such competition would probably increase with group size. An examination of these expectations constituted the objective of this study.

\section{Results and Discussion}

Records on the birthweights of 33,165 pigs born in 3282 litters over 14 separate seasons on a single farm formed the data. For each litter size at birth, ranging from 1 to 19 , an analysis of variance partitioned the total corrected sum of squares into portions ascribed to season, litters within season, and pigs within litters and season. Table 1 contains the within component, $\hat{\sigma}_{e}^{2}$, and the intra-class correlation for each litter size. The table shows the trend toward increasing variance within litters and a corresponding decline in the intra-class correlation as litter size increases. A graph of the results in Figure 1 leaves no question that in these data the intra-class correlation declines in a linear manner with increasing litter size. The equation of the line fit through the means by the method of least squares, weighted by the number of litters in each group, came out as: $\hat{\rho}=0.84-0.044$ (Littersize) with the residual mean square based on 16 degrees freedom equal to 1.15 . The $\rho$ from litter size equal one was not included as it represents an artifact forced by the formula. No estimate of $\hat{\sigma}_{e}^{2}$ exists and $\rho$ is not defined in litters of one. We modified Table 1 by showing the values of $\hat{\sigma}_{e}^{2}$ and $\hat{\rho}$ as missing for litter size one.

Further analyses sought to check for breed and sex effects on this phenomenon but could detect none. The animals from a litter in the study grew from birth to 154 days in the same pen. Weaning occurred at 42 days. The animals received feed ad libitum. An analysis of weights taken 21,42, 98, and 154 days after birth showed the same (but less pronounced) trend in estimates of the intra-class correlation as occurred in birth weights. In each case a linear model relating intra-class correlation to litter size fit well with a negative slope significantly different from zero $(\mathrm{P}<0.05)$. Obviously, postnatal competition within litters depends on management used in handling and feeding the animals. Some residual effect of the prenatal environment could remain, at least for the first few weeks of postnatal life. These findings suggest the possibility of within pen competition and perhaps the effects of such need consideration in planning facilities for pigs raised in confinement. 


\section{Summary}

The intra-class correlation for birth weight in litters of pigs depends on litter size, declining linearly with increasing litter size. An explanation could include prenatal competition for space and nutrients.

\section{$5 \quad$ Acknowledgements}

The authors thank Gordon Thomson for original discussions on this topic.

\section{References}

[1] Snedecor, G.W. and W.G. Cochran. Statistical Methods, 8th edition, 1989. Iowa State University Press, Ames, Iowa. Section 13.5, page 342.

Table 1: Intra-class correlations from within groups defined by litter size

\begin{tabular}{rrrrc} 
Litter & Number of & Number of & & \\
Size & Pigs & Litters & $\hat{\sigma}_{e}^{2}$ & $\hat{\rho}=\hat{\sigma}_{g}^{2} /\left(\hat{\sigma}_{g}^{2}+\hat{\sigma}_{e}^{2}\right)$ \\
\hline 1 & 7 & 7 &. &. \\
2 & 68 & 34 & 25.9 & 0.56 \\
3 & 114 & 58 & 19.6 & 0.63 \\
4 & 232 & 104 & 21.4 & 0.61 \\
5 & 520 & 149 & 19.6 & 0.65 \\
6 & 894 & 199 & 19.8 & 0.58 \\
7 & 1393 & 274 & 21.7 & 0.56 \\
8 & 2192 & 415 & 23.4 & 0.51 \\
9 & 3735 & 444 & 25.9 & 0.45 \\
10 & 4440 & 472 & 26.1 & 0.37 \\
11 & 5192 & 388 & 29.7 & 0.37 \\
12 & 4656 & 345 & 31.5 & 0.33 \\
13 & 4485 & 190 & 32.0 & 0.25 \\
14 & 2660 & 100 & 34.5 & 0.23 \\
15 & 1500 & 41 & 37.7 & 0.14 \\
16 & 656 & 14 & 33.6 & 0.19 \\
17 & 238 & 7 & 38.8 & 0.13 \\
18 & 126 & 3 & 34.2 & 0.10 \\
19 & 57 & 3282 & & 0.00 \\
\hline total & 33165 & & &
\end{tabular}




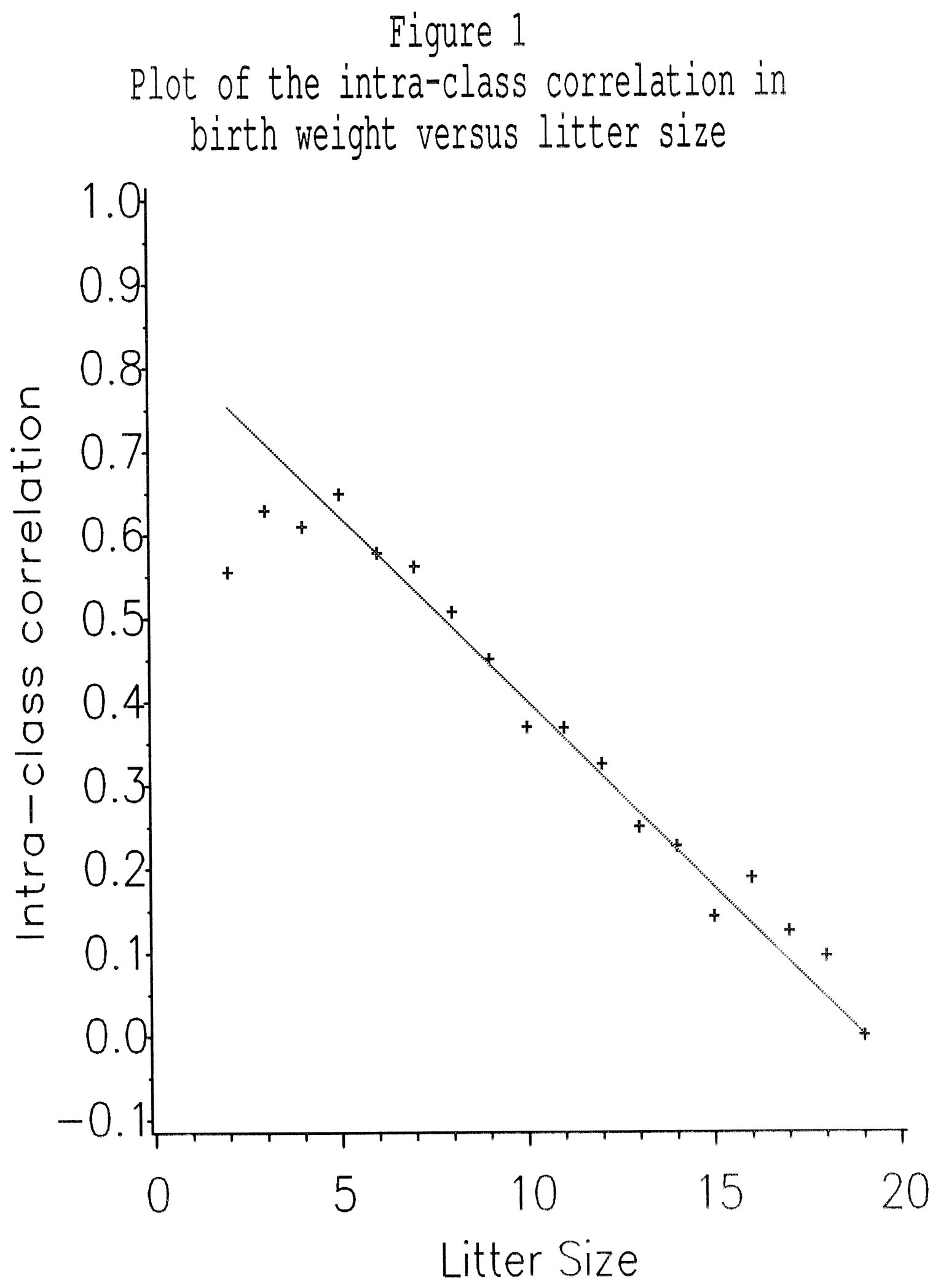

